\title{
A Multiple Perspective Case Study of a Young Adult with Intellectual Disabilities Participating in a Pre-service Teacher Education Class
}

\author{
James Wintle \\ Queen's University
}

\begin{abstract}
For adults with intellectual disabilities, the opportunity to attend a postsecondary institution is increasingly becoming reality. Although there is a growing body of literature documenting examples of inclusive postsecondary education, there is a lack of information detailing the experiences of pre-service teacher candidates (TCs) who are enrolled in inclusive courses. The purpose of this interview study using case-study methods was to describe the challenges and benefits of an inclusive class in a 1-year, after-degree professional teacher education program from the perspectives of 5 TCs enrolled in a course audited by a young woman with an $I D$, as well as from the perspective of the course instructor. The classmates and course instructor provided positive responses regarding their experiences in the inclusive class, such as seeing inclusion in practice. Negative responses concerned whether or not a curriculum class in the teacher education program was the right fit for the student with ID.
\end{abstract}

The practice of including adults with intellectual disabilities (ID) in postsecondary classes with their typically developing peers has been a growing phenomenon since the 1980s (Neubert, Moon, Grigal, \& Redd, 2001). When inclusive postsecondary education (IPSE) occurs in a teacher education program it can provide a unique opportunity for pre-service teacher candidates (TCs) to learn alongside peers with ID in a structured environment. Interacting with individuals with ID in a structured environment has been shown to positively influence typically developing peers' views on individuals with ID (Acton \& Zarbatany, 1988). In this study, a young woman with ID audited a drama curriculum class in a 1-year professional Bachelor of Education program in Ontario, Canada. Five of her typically-developing classmates and her course instructor were interviewed to find how they interpreted their experience in an inclusive class.

Recently, ideas about what it means to be disabled have shifted based on a social model of disability, and elementary and secondary schools in Canada have adopted more inclusive practices (Hutchinson, 2010; Rapley, 2004). This shift to progressively heterogeneous classrooms means that teachers are required to integrate students with various abilities into their classes. It 
has long been accepted that teachers' expectations can influence their students' educational outcomes (Campbell, Gilmore, \& Cuskelly, 2003). Thus studying how TCs interpret the experience of learning alongside someone with ID may provide insight into how to prepare TCs for teaching in inclusive classrooms.

In North America, inclusive education has been shaped by various pieces of legislation (e.g., the American Education for All Children Act of 1975, the Ontario Education Amendment Act of 1980). Least Restrictive Environment provisions mean that students with ID are now often educated in regular classrooms (Philpott, 2001). Unfortunately, access to postsecondary education for individuals with ID has not kept pace with access to elementary and secondary education. Recently, the American Higher Education Opportunities Act of 2008 has addressed the issue of access to financial aid for students with ID attending postsecondary institutions, helping students with ID overcome financial barriers of attending postsecondary education (Hart, Grigal, \& Weir, 2010).

IPSE originated in Alberta, Canada, where parents of young adults with ID and allies collaborated with the University of Alberta to create an inclusive on-campus program in 1987 (Weinkauf, 2002). IPSE makes use of person-centred planning to identify appropriate postsecondary courses and supports based on what the student needs and wants (Think College, 2011). Mentors are often utilized to enhance the academic experience for students with ID (Think College, 2011). Studies have shown that students with ID who have attended inclusive postsecondary classes have improved their academic, social, and vocational skills, and have attained higher rates of employment than students with ID who did not attend postsecondary classes (Casale-Giannola \& Kamens, 2006; Neubert \& Moon, 2006; Zafft, Hart, \& Zimbrich, 2004). Understanding and disseminating how classmates without ID and class instructors view the challenges and benefits of such an experience will be an initial and important step in promoting meaningful educational opportunities for adults with ID.

\section{Purpose}

A search of the literature reveals no studies documenting IPSE in a 1-year, professional teacher education program. Thus the purpose of this study was to describe the challenges and benefits of an inclusive class in a professional teacher education program from the perspectives of those enrolled in the class and of the course instructor. While some studies have shown that TCs and in-service teachers are positively disposed to inclusion, others have revealed ambivalent or even negative dispositions toward inclusion (Cardona, 2009; Forlin, Douglas, \& Hattie, 1996; Ryan, 2009). This underscores the potential of pre-service teacher education programs, as they can expose future teachers to learners with ID in an inclusive environment and potentially promote more positive dispositions toward inclusion. Studies have demonstrated that it is possible to promote a shift to more positive attitudes toward people with ID (Acton \& Zarbatany, 1988; Donaldson, 1980; Eiginbroad \& Retish, 1988; Esposito \& Peach, 1983). However, these studies imply that contact must be direct, structured, organized along a meaningful dimension, and include equal status, and that the quality of the contact influences attitudes. Such contact between TCs and students with ID has been studied by Carroll, Petroff, and Blumberg (2009). They interviewed 12 TCs (mixed undergraduate and graduate level) participating in a non-credit bearing IPSE course. They found that most TCs finished the course with a stronger commitment to inclusive teaching practice.

The design of the current study has been informed by the main research question: What do the TCs and the course instructor perceive to be the challenges and benefits of this experience? 
This question was intended to address the absence of data concerning TCs' views on IPSE in preservice education. The perspective of the student with ID was also sought and is reported in Wintle (2010).

\section{Method}

A qualitative design utilizing a multiple perspective case study method was employed to describe and analyze participants' actions, beliefs, thoughts, and perceptions (McMillan \& Schumacher, 2006). The strength of the case study method is its ability to examine a phenomenon in a real life context (Yin, 2006). The advantage of employing multiple perspectives within a case study is the thick description (Geertz, 1973) this approach provides. The intention was to describe not only the observed behaviour of the participants, but the context of that behaviour as well, to render it meaningful to others (Geertz, 1973). By recording the experiences of the multiple participants, as well as their perspectives, this case study research may help others to compare, contrast, and develop meaning related to the subject and views presented (Stake, 1994).

\section{Research Setting and Setting Selection}

Data collection occurred at a faculty of education in a mid-sized university in eastern Ontario. The teacher education program at the university is an 8-month, after-degree professional program (all TCs enrolled in the Bachelor of Education program have previously completed an undergraduate degree). The program is divided into on-campus periods and practice teaching, or practica, periods off campus. Data collection at the faculty of education occurred during the winter semester. The TCs were present for the first 7 weeks of the winter semester, before leaving for a teaching practicum. However, due to schedule changes for the drama curriculum course audited by the student with ID, she was only able to attend classes during the first 6 weeks of the winter semester. Thus data collection occurred during this 6-week period. Observations took place in the drama curriculum room. Interviews were held in a separate, private room.

\section{Participants and Participant Selection}

The participants in this study included five TCs, the instructor of the drama curriculum class, and a young woman with ID, Laura (a pseudonym), auditing the class.

The teacher education program attracts students from across Canada and across different age brackets, although most students are in their early 20 s. They come to the university with differing knowledge of, and experience working with, people with ID. During the winter semester, they attend several classes on different topics during two on-campus sessions, divided by an extended period of teaching practicum in schools off campus. The inclusive class that I observed, drama curriculum, was a mandatory course for TCs earning qualification to teach intermediate/senior (grades 7 through 12) drama. There were 28 students enrolled in the class, 23 women and 5 men. The class met twice weekly, on Mondays in the morning and on Thursdays in the afternoon, for a total of 5 hours each week.

I interviewed five TCs from the drama curriculum class who volunteered to participate in the study: Candice, Norah, Beverly, Olivia, and Stephanie (all pseudonyms). Laura was in the same class work group as Candice, Beverly, and Stephanie. Stephanie was one of Laura's two "buddies"- students who volunteered to help Laura with course work and note taking. Norah and Olivia were classmates but worked less closely with Laura. Each of the TCs had just completed an undergraduate honour's degree the previous academic year except Norah. I chose the 
TC interview participants by convenience sampling while representing both Laura's work group members and her classmates. While this type of sampling facilitated the research, I note that the findings from these interviews will not be generalizable beyond TCs with similar characteristics. I will describe the five TCs to show the extent to which their characteristics reflect those of BEd students in general (McMillan \& Schumacher, 2006). Three of the TCs (Candice, Olivia, and Stephanie) had considerable previous experience working with individuals with ID, while two of the TCs (Norah and Beverly) did not.

Candice had experience working with students with exceptionalities in her previous practica. Also, as a swimming instructor, she taught children with disabilities. These experiences included working with students and children with fetal alcohol spectrum disorder, autism spectrum disorder, obsessive-compulsive disorder, giftedness, plus experience with IPSE. During her honours degree, Candice was enrolled in an inclusive dramatic arts acting class that included students with ID.

While completing her honours degree, Olivia spent two of her summer breaks working at a summer camp operated by a school board in the Toronto area. Her job entailed working specifically with children with exceptionalities, such as fetal alcohol spectrum disorder and Down syndrome. One of Olivia's practica was in a Grade 9 classroom that used a curriculum focused on basic skills for reading and writing.

Stephanie had prior experience working with children with exceptionalities, first as a babysitter, and later as a camp counsellor. As a babysitter she worked for a family who had a child with Down syndrome. As a camp counsellor she worked for the city of Toronto integrating children with exceptionalities into camp activities by adapting activities to make them more accessible.

After completing her honour's degree, Norah taught English for a brief time in Korea before returning to Ontario for her Education degree. Norah had limited experience working with individuals with exceptionalities, although she reported that when she was younger she had a friend who had ID.

Beverly completed her honours degree at the same university, prior to entering the education program. She reported having little prior experience with individuals with ID, apart from some integration in high school physical education classes.

Kelly (a pseudonym), a second year $\mathrm{PhD}$ candidate in Curriculum Studies, taught the drama curriculum class during the second semester. Kelly completed her undergraduate degree in drama and English in Ontario before pursuing an MA in theatre. After working in theatre, she completed a 1-year teacher education program in Ontario, qualifying her to teach at the secondary level. She also completed Special Education, Part One, a 125-hour course, as an additional qualification course, and taught at the secondary level for 5 years. Kelly's prior experience with individuals with ID included work in schools as a teacher and life in her home with her younger brother diagnosed with an ID. Additionally, in her first year in the PhD program, Kelly was a teaching assistant for the drama curriculum course. That year another student with ID audited the course. Kelly considered it an enriching experience for the TCs and cited it as one of the reasons, in addition to her other experiences, that made her agree to include a student with ID in her drama curriculum course.

Laura was a 26-year-old student. In addition to having an ID, Laura has a seizure disorder. Many disorders that cause ID are characterized by "behavioural phenotypes"-differences in behavioural and developmental conditions compared to those without the disorder. Although specific phenotypes are consistently associated with specific syndromes, there is some within- 
syndrome variability as well (Hodapp \& Dykens, 2007). Given this variability, limitations to generalizability are noted.

Since the age of 18, Laura has lived in a homeshare - an arrangement where she lives with a family who is compensated for room and board and for care and supervision. Laura graduated from a special education secondary school program in 2004. She reported having difficulty finding employment since then. She is an outgoing person, with what can be described as a bubbly personality. Laura is independent in her self-care and she routinely uses public transportation by herself. I met Laura at the Community Adult Learning Centre (CALC) Prep program (a pseudonym) during the fall semester when I was invited to meet CALC Prep students and observe their classes. CALC Prep operates as a 10-month preparatory program for adults at least 21 years old with ID who are interested in experiencing postsecondary education. While at CALC Prep, students work on literacy, numeracy, and computer skills, as well as goal setting. CALC Prep students can participate in this preparatory program multiple times until they are ready to audit courses at the university. For a more thorough description of CALC Prep, see Wintle (2010). CALC Prep did not formally assess students' cognitive abilities; however, based on professional experience and approximately 80 hours of observation at CALC Prep, I estimated Laura's literacy skills to be similar to those of an 8-year-old and her social skills to be similar to those of a 12year-old.

This was Laura's second year at CALC Prep, and her second time auditing a course at the university. In the preceding year, she audited a music curriculum class in the teacher education program. In the current session, Laura audited the drama curriculum class because she expressed an interest in taking a drama course and because Kelly volunteered to open the class to a student from CALC Prep. I asked Laura to be a participant when I observed her in the CALC Prep program. She always seemed happy to see me and, when I approached her about being a participant, she appeared genuinely excited.

\section{Observations at the University}

I observed one drama curriculum class a week during the first 6 weeks of the winter term, for a total of approximately 11 hours. In an effort to mitigate any Hawthorne effect, I chose not to participate in classroom activities or interrupt the social interactions in the classes (Miller \& Salkind, 2002). I sat in a corner of the room behind the circle of chairs the students sat in, where I would have a clear view of Laura. From there, I made observations of Laura's interactions with the TCs and with the class instructor. Observations allowed me to record behaviour in field notes as it occurred naturally in the classroom (McMillan \& Schumacher, 2006). Continuous observation was used to describe the behaviour of the student with ID, with the aim of developing a portrait of the interactions involving her and her peers. I focused on the nature of the interactions between Laura and her classmates and instructor, and on who initiated these interactions. I also paid attention to the quality of the interactions and their evolution over the 6-week period to see if there was a noticeable change.

\section{Interviews with the TCs and Kelly}

I conducted two individual, semi-structured interviews with each of the five TCs and the course instructor to answer the research question. I chose this approach because a semistructured method would allow me the flexibility to raise new questions in response to what an interviewee might say (Patton, 2002). An interview guide was used to ensure that similar questions were used with each TC (Patton, 2002). Using a different set of questions, I also 
interviewed Kelly, the class instructor. Five TCs were interviewed given the time constraints of collecting data over 6 weeks of one term. I conducted interviews with the TCs and instructor twice over the course of the first 6 weeks of the winter term. The first set of interviews was conducted during the second week of the 6-week term, and the second set was conducted at the end of the 6-week period. Approximately five weeks lapsed between interviews. These particular times allowed me to record any possible changes in the TCs' beliefs as the term progressed. Each interview lasted approximately 15-20 minutes.

Questions I asked the TCs focused on the experience of learning alongside a student with ID. Examples of TC questions include: Has this experience had an impact on your future career as an educator? Do you think Laura's presence adds to the experience of being a BEd student? Questions I asked Kelly focused on teaching an inclusive class. For example, what were your concerns when you were asked if a student with an intellectual disability could audit your class? What advice would you give to a professor who's contemplating teaching an inclusive postsecondary class?

The design of the questions was influenced by interview questions used and findings reported in previous interview studies, particularly Mosoff, Greenholts, and Hurtado (2009), and Hamill (2003). Prior to commencing each interview, I reminded the interviewee that anonymity would be protected and that they could choose to not answer any question. All interviews were audio-recorded and transcribed verbatim.

\section{Data Analysis}

I analyzed data from both observations and interviews as a means of data reduction and sense-making (Patton, 2002). This was done to identify the core consistencies across the data (Patton, 2002). From the patterns that I found, themes emerged. An inductive, open coding approach was used early in the analysis. Eventually, data analysis became more deductive as the data became saturated. However, I remained vigilant to possible anomalous behaviours (outliers) that did not fit with preliminary conclusions, rather than excluding them as aberrant (Dewalt \& Dewalt, 2002).

I carried out the analysis of the observation data using photocopies of the original field notes. This was done in order to maintain the integrity of the raw data. Analysis proceeded by writing codes in ledgers. I then arranged the coded data visually to allow for comparisons and to answer the specific research question.

I had digitally voice-recorded all interviews to ensure accurate, verbatim transcription and reporting of participants' views. The interview transcripts were then coded using the qualitative research program ATLAS.ti. This allowed me to arrange the interview data by theme, in order to answer the specific research question. I identified significant statements from each individual's transcripts that captured the meaning of the phenomenon and the beliefs of that participant. I combined overlapping and redundant significant statements into a small number of themes that described the meaning of the experience for the individual (Miller \& Salkind, 2002). As a form of member checking, I gave transcripts to interview participants for review and asked them to suggest any changes or clarifications of their statements. None of the participants asked that any changes be made.

In an effort to increase external validity of the results, I triangulated the data. Having data from the observations, as well as from multiple interview participants, ensured that multiple perspectives could be drawn from in order to answer the research question. I sought regularities in the data by comparing the findings of the field observations and coded interviews. 


\section{Findings}

The research question was answered through an analysis of interview data and observations of the drama curriculum class. While there were some differences in the intensity of responses from the interviewees, often due to the extent of the interviewees' interactions with Laura, overall there was a great deal of agreement on the nature of the IPSE experience. The data yielded two themes: (a) challenges and (b) mutual benefits. Challenges focused on the difficulties that the TCs and Kelly experienced. Mutual benefits focused on the benefits the TCs and Kelly derived from the experience of having Laura included in their class. Themes and subthemes can be seen in Table 1 .

In order to contextualize these findings, I provide a brief description of Laura's behaviour in the drama class based on my observations over 11 hours. At the beginning of the observation period I observed that Laura was reserved in class-wide activities, but readily interacted with members of her class work group. When Kelly lectured, Laura would often become disinterested and turn her attention elsewhere such as going through her school bag or checking her phone for messages. She would write notes off the blackboard when the class was instructed to do so, but often fell behind and would not complete the note before it was erased. On these occasions, her class buddies would lend her their own notes so she could finish writing what was written on the board. As the semester progressed, Laura interacted with more of her classmates. By the end of the observation period I observed that she was treated less like a stranger and more like a classmate by the TCs in the class.

\section{Challenges}

Although the TCs and Kelly were genuinely open to the idea of an inclusive class, the experience was not without its challenges. Some of these challenges appeared before Laura joined the drama class and were present throughout the entire study period.

Lack of information. In the first set of interviews, three of the TCs communicated to me that they wished they had been given more information about Laura and about her learning expectations in the drama curriculum class. Candice, for instance, said that she wondered how the class was supposed to "tailor things to include" Laura, given that Laura "was not coming from the same background at all" as the TCs (C., int. 1). She also wanted to know what Laura's expectations were in the drama curriculum class. Stephanie reported that the TCs were unsure of why Laura was in a curriculum class, saying, "We don't know what her purpose is in the class; my understanding is that Laura thinks we're in a drama class, not a drama curriculum class" (S., int. 1). Stephanie, speaking as Laura's buddy, also felt that she did not know enough about Laura to be able to help her. She said that it was hard being Laura's buddy when she did not know what Laura was supposed to take away from the experience. Norah stated that when she first learned a

Table 1

Themes with Sub-themes

\begin{tabular}{ll}
\hline Themes & Sub-themes \\
\hline Challenges & Lack of information \\
& Is this the right fit? \\
& Worrying about being offensive \\
Mutual benefits & Professional benefits \\
& Personal benefits \\
\hline
\end{tabular}


student with ID would be joining the class she wanted to know what kind of ID the student had. Since different IDs have different behavioural phenotypes (Hodapp \& Dykens, 2007), it is understandable that the TCs would want to know what ID their new classmate has, as this might help them to prepare proactively for an inclusive environment.

In the second round of interviews, Norah still reported that having more information on the nature of Laura's ID would be helpful. As she put it,

I think having an understanding of what she's capable of and the intellectual disability that she has, I think would be beneficial to students that are in a classroom with her so they can gauge what things they can and can't do or what things they [can] expect of her. (N., int. 2)

Such information, when used for the planning of supports, can contribute to a person-centred approach that can enhance outcomes for the student with ID (Schalock et al., 2010). However, Norah did note that Laura may have wanted "to be treated like everybody else," and therefore may have wanted this information to be kept private (N., int. 2). In the second round of interviews, Beverly also reported a lack of information. Similar to Candice, she mentioned that she was not sure what Laura's expectations were and what Laura was supposed to be learning from being in the drama curriculum class.

Is this the right fit? In the first set of interviews, three of the TCs and Kelly made reference to the fact that because Laura was not actually a teacher education student, she might have a difficult time connecting with the TCs and with the curriculum. In Kelly's first interview she reported a concern that Laura might have a difficult time integrating socially with her classmates. She pointed out that the TCs had bonded since September and that it would be difficult for anyone to join a class after an entire semester had passed. She also noted that Laura would not be participating in any practicum,

I think the fact that she won't be doing a teaching practicum might be a little bit of a barrier, too...in terms of bonding experiences.... What happens out on practicum is huge in terms of the class's shared identity or sense of purpose.... and unfortunately, there's no way to really replicate those experiences for her. (K., int. 1)

Beverly raised a similar point. She reported that Laura was not as socially integrated as she could be due to the TCs bonding over the previous semester, as well as the fact that the TCs spent the whole school week together, while Laura was only present for two classes each week. I also made a note on Laura's social integration. Just before I observed the drama curriculum class for the third time, I encountered Laura outside the classroom. She informed me that she had missed the Monday class that week because it was cancelled due to a special presentation for all the TCs. My interpretation was that even when the TCs are on campus, there are many interruptions that can result in fewer classes. I wondered whether the amount of time Laura would be spending with the TCs provided enough social interaction to be of benefit for her.

Beverly also commented on the disconnect Laura experienced with the curriculum. She reported that Laura refrained from participating in the academic class discussions. In Beverly's opinion, participating in these discussions would be difficult regardless of whether one had ID or not, because participating in such discussions requires experience in teaching. Beverly also made reference to a particular group assignment on unit planning. She and Laura belonged to the same group, and she felt that Laura was not benefiting from this assignment since it was not relevant to a person without a practicum experience. Beverly was concerned that Laura was encountering difficulty during group assignments because of the common vocabulary surrounding pedagogy 
that the TCs employed as a result of their common experiences in the teacher education program. She felt some of the language used was beyond Laura's comprehension, which contributed to Laura's difficulty participating in group assignments.

Candice reiterated Beverly's concern about the academic work being so reliant on having experience in a teaching practicum. Candice also questioned whether Laura was engaged during discussions of practicum and curricula. Her view was that Laura was not engaged at these times. This was a concern that I reported during observations of the class. During Laura's first class, I recorded in my field notes, "Class discusses rubrics. Laura listens to the other students. Laura starts going through her things, taking things out of her bag" (FN., 7/1/10). This apparent loss of interest in the class discussion led me to speculate that "Perhaps she is bored; the topic is not one that she would be familiar with since she has not been on practicum" (FN., 7/1/10). I made similar comments during subsequent classes. Observation data tend to corroborate Candice's suspicion that during times when discussions focused on pedagogy, Laura was not engaged as the discussion was outside of her experiences.

Candice and Stephanie both raised the concern that they were in a drama curriculum class, not a drama class. Stephanie felt that Laura was not made aware of this distinction, while Candice reported,

It's not a drama class, it's a curriculum class, and it's not very practical and so much of what we're talking about is based on our experiences as teacher candidates in practicum...it's not like in an acting class, [where] so much of what you're doing is physical or you're working in groups and you're being an audience member and you're watching. (C., int. 1)

The TCs' comments seemed to underscore a sentiment that perhaps the teacher education program would not provide Laura with the same opportunities to connect and participate as an undergraduate drama course would.

In the second round of interviews, Kelly and Beverly still alluded to not being sure if the drama curriculum class was the right fit for Laura. As well, in her second interview, Olivia raised concerns about the compatibility of the teacher education program with the goal of providing Laura with an experience she would find meaningful. Kelly expressed a concern that she could not make the theory aspect of the course relevant to Laura because it pertained to teaching, and Laura was not going to go on a practicum or become a teacher. She felt that attempting to make the theory comprehensible to Laura would require her to present concepts to the TCs in too basic a fashion, which would be inappropriate given that the TCs have already graduated with a bachelor's degree. I think that Kelly's feelings can best be summarized in her statement that "the reality of it is it is a BEd program, and they're here for teaching, and not just drama" (K., int. 2).

Beverly reported this incongruence between the needs of the TCs and creating a curriculum that was accessible for Laura,

Last class we spent an hour discussing everyone's practicum experience and [Laura] didn't participate in that because she didn't do a practicum, and it didn't feel like she felt comfortable commenting on the discussion at all...I don't think it was completely boring for her, but I don't think it's necessarily the most valuable use of her time. So, I don't know, I think it's hard for Kelly to balance that. (B., int. 2)

In addition to raising a concern with the academic fit, Beverly also made reference to the social fit in her second interview. She mentioned how, after returning from a practicum, TCs would ask each other about their teaching experiences. She pointed out that these conversations, typical among TCs, were not possible with Laura since she was not completing any practicum. 
Olivia's concern was about the disruption caused by the upcoming practicum. She reported that Laura was participating more and more with each class, and she was afraid that such a long break away from the drama curriculum class might cause Laura to "crawl back into her shell" and not feel as comfortable with the TCs as she currently did (O., int. 2).

Worrying about being offensive. The interviews with the TCs and Kelly also revealed that they encountered a number of additional, wide-ranging challenges that they did not foresee before Laura joined their class. These challenges centred on the fear of offending Laura directly in the way they spoke to her or indirectly by allowing her presence in the class to amount to tokenism. During the first interviews with Stephanie and Candice, there was a sense of frustration with how the inclusion of Laura was progressing. Stephanie made her feelings known when she said,

I just do not think that it's working in this classroom, and I think that it's really unfortunate that it's not working. I feel like Laura is not being treated like a person....I feel like she is the student in our class with an intellectual disability and she's just supposed to sit there and look pretty and I'm very upset by it. (S., int. 1)

Stephanie went on to explain that she was experiencing some difficulty as Laura's buddy because she was not given enough information about how to help Laura. Her feelings were also a result of the lack of opportunities Laura was given academically in the class. She felt that Laura, with her help and the help of the second buddy, could be given more responsibilities in group assignments. While Stephanie did say that she felt the idea of including Laura in the drama curriculum class was wonderful, the impression that I was left with was that she felt Laura's presence in the class amounted to tokenism.

I detected a similar sense of frustration during the first interview with Candice. She remarked on how eager Laura was at the beginning of each class, but that as the class progressed, Laura seemed to become disconnected. Candice said that she felt the design of the course did not create an inclusive environment. At the time of the first interviews, Stephanie and Candice had spent the most amount of time interacting with Laura of any of the interviewees, and thus it is not surprising then that they were the first to report additional challenges associated with this experience. However, by the second round of interviews Beverly, Norah, and Kelly had also reported challenges with the experience, in addition to Stephanie and Candice reporting further challenges.

One particular issue that came up in the second round of interviews related to communicating with Laura. Candice, Stephanie, and Beverly each commented that they had been communicating with Laura outside of class through email or Facebook. They each reported having difficulty with this since they did not always understand what Laura was trying to say. Candice, for instance, said, "Face-to-face, I totally know that she means...but when she's writing to me, I have no idea sometimes, and that's really hard, because I want to respond, except I have no idea what I'm responding to" (C., int. 2). For Kelly, the issue of communicating with Laura through email was one of professional boundaries. She said that Laura would send her personal emails, even after she spoke to Laura about boundary issues. Norah remarked on the occasional unease some of the TCs felt when communicating with Laura. She reported that many of the TCs were not sure how to approach her or how to talk to her at times,

I think, especially if [Laura's] not sure what to do in a situation, then no one really knows what to say. Or if she makes a comment that someone might not agree with, maybe someone might be less inclined to challenge it. (N., int. 2) 
Stephanie, who commented that during group work it was difficult to respond to Laura's ideas when they were not relevant to the topic at hand, expressed similar sentiments.

Another challenge reported by Stephanie was specific to being Laura's buddy. Stephanie commented that she enjoyed being Laura's buddy, but at times was not sure how to proceed,

I'm always scared of offending her, leading her too much by the hand and spoon-feeding her too much, but then there's times when I am paying too much attention to that so I'll leave her too far behind, and so it's like there's a very fine line between helping and then going over the line. (S., int. 2)

Stephanie went on to say that she was not sure how to properly ask Laura questions, such as whether or not she needed help. This challenge is not surprising, given that although Stephanie had prior experience working with individuals with ID, she did not have experience working with individuals with ID in an academic setting, particularly with individuals the same age as her. As well, she did not receive specific training or instruction on how to be Laura's buddy, nor was she given the opportunity to meet Laura prior to her inclusion in the drama curriculum class.

\section{Mutual Benefits}

The second theme centred on the mutually beneficial nature of the IPSE experience. In the interviews with Laura, she reported ways in which she benefitted from her experience in the drama curriculum class. These included learning about herself, being independent, having responsibilities, learning new things, and being social. For a more thorough description of Laura's experience, see Wintle (2010). Throughout the interviews with the TCs and Kelly, they also reported ways in which they benefitted from the IPSE experience. Hamill (2003) found mutual benefits of the IPSE experience for classmates and faculty. Similarly to Hamill, I identified subthemes of professional benefits and personal benefits.

Professional benefits. Each of the TCs identified ways the experience would help them as future educators. In the first round of interviews, all five of the TCs reported that as future educators, they will be teaching in classrooms that have students with different ability levels. Being part of an inclusive classroom during their teacher education would provide an opportunity to see inclusion in action. Their instructor, Kelly, highlighted this point when she said,

I'm a big believer in experience rather than just being told this is how it is to work with someone with special needs...I have no doubt that whatever class they take here for Special Ed is probably wonderful, but I don’t think it can possibly replace first-hand experience. (K., int. 1)

Olivia and Norah each felt that the experience enhanced their learning because it reminded them to acknowledge different learning needs. Candice reported that all learners are different, so the more experience the TCs gain with learners with different needs, the better. Stephanie suggested that the experience went beyond the standard teacher education experience of preparing lessons to include hypothetical students with ID, because the presence of Laura gave the TCs exposure to something tangible, since a future student in their class could be like Laura. Stephanie and Norah both commented on the positive effect that the experience could have on creating acceptance and breaking down preconceived notions of students' abilities.

Over the course of the observation period, the TCs gained more experience interacting with Laura. During the second round of interviews, the TCs articulated benefits of this IPSE experience. Norah, for example, felt that drama was a good environment to integrate students with ID because there "is an opportunity for them to contribute just as much as anybody else to the dy- 
namic of the classroom" (N., int. 2). Norah mentioned that as a teacher she would employ a similar buddy system to that used in the drama curriculum class, except she would want a new buddy each week. She felt that would provide more opportunities for positive interaction. Norah also said that students with ID are often stereotyped as not being able to participate. She said that this experience had helped her to realize that individuals with ID are capable of participating to a great extent within the classroom, "if you take the time to listen to what they have to say" (N., int. 2). Norah went on to say that the IPSE experience had made her more conscious of the need to actively think about how to accommodate her students when she is a teacher. Norah concluded her interview by stating that her time in the inclusive class had been "a great experience," and that more university courses, especially in faculties of education, should be made inclusive (N., int. 2).

The four other TCs made remarks similar to those of Norah. Olivia, for instance, commented on student ability levels, especially in drama classes, which are often hands-on, and provide frequent opportunities for group work. Noting that Laura was often less outgoing in large group activities, Olivia said that as a teacher she would place more emphasis on small group activities in her future classes as a way of promoting participation of students with ID. Olivia, Stephanie, Beverly, and Candice all stated that having someone with ID integrated in a teacher education class was beneficial because it allowed TCs to see inclusion in action. Stephanie also reported that the experience gave her a greater awareness of ID and broadened her perspectives. Beverly commented on wanting to become more familiar with her students' needs,

I think one thing, on my first couple practicums, I didn't read my students' IEPs, and I didn't really know what they needed that much, and I was more figuring it out as I went, and I think incorporating that into my planning is important. (B., int. 2)

Beverly reported that this experience made her think more about what she will do as a teacher to make her lessons relevant for students with ID, and how she can promote participation by all her students. Candice commented that she felt more comfortable talking about students' needs with them, rather than trying to figure them out on her own. She also reported being more confident teaching integrated classes,

I know some schools are trying to have more integrated classes, and I think I'll be really open to it, because I've had this experience...I think I'm interested in it in a way I wasn't before, and I'm definitely more confident in it. (C., int. 2)

Kelly identified ways in which the TCs would benefit, as well as identifying benefits to her own teaching. Kelly felt the experience would remind the TCs that not all students can construct meaning from abstract theories, and therefore this experience had been a good way for the TCs to become aware of the need to incorporate "a concrete, tangible part to things, instead of just keeping everything abstract" (K., int. 2). In terms of her own teaching, Kelly indicated that the experience had helped her to be more cognizant of differentiated teaching methods. As well, she thought the experience made her more mindful of making sure that what she was teaching was comprehensible.

Throughout observations of the class, I also noticed ways in which the TCs benefited professionally. Numerous times, individual TCs answered Laura's questions or explained material to her. For instance, in Laura's first class, I observed one of the students explaining to Laura what curriculum documents are. Each time one of the TCs helped Laura to better understand the course material can be seen as practice for future times when the TCs have classes of their own. 
It is likely they will have students with ID in their classes, and the experience they have gained working with Laura will help them to create inclusive learning environments.

Personal benefits. In addition to the professional benefits that the TCs cited, a number mentioned gaining personal benefits from the experience of having Laura included in their class. Four of the TCs commented on enjoying getting to know and spend time with Laura, and described Laura using language that suggested they considered her a peer in more than just an academic sense. For instance, Beverly said,

I guess it's made me more positive about adults with intellectual disabilities, because I've worked with young people with intellectual disabilities and in high school known people and stuff, but I haven't really made friends with any adults with intellectual disabilities before...I find it really easy to have a conversation with Laura, and I feel like her life is similar to my life, and we can be friends. (B., int. 2)

Olivia said that she thought of Laura as a peer and not as "an outsider who you're helping because of the special need that she has" (O., int. 2). She went on to say that she really liked interacting with Laura and that the way she treated Laura was the way she would treat any of her peers in the drama curriculum class. Candice reported how much she enjoyed Laura's presence in the class and that she often talked with Laura before class. Stephanie also commented that she enjoyed Laura's presence and liked working with her. She said, "I just love her so much...she's just a treat to be with and she's just so much fun" (S., int. 2). As well, Stephanie appreciated how much Laura loved being a part of the drama curriculum class and her love of life in general, and described this love of life as being infectious.

\section{Discussion}

The purpose of this study was to describe how TCs and a class instructor view the challenges and benefits of IPSE in a professional teacher education program. Interview data and observations of the drama curriculum class revealed that the TCs became more comfortable with the student with ID, eventually seeing her as a classmate. Casale-Giannola and Kamens (2006) similarly found that by the end of an inclusive course, non-disabled students began to report a classmate with ID as "just another student" in the class (p. 348). Similar to results in Hamill (2003), interview data from the TCs revealed that there was a mutually beneficial nature to the IPSE experience. Not only did the TCs believe that the student with ID benefited from the experience, but they also benefited by seeing inclusion in action. The TCs gave several examples of how the IPSE experience had made them think about ways to promote inclusion in their classes when they are teachers. The TCs also mentioned personal benefits, such as knowing the student with ID, which they gained from the experience of having the student with ID included in their class.

This study adds to the literature by describing challenges of the IPSE experience different from challenges that have already been reported. Past literature has reported few challenges; in particular, Casale-Giannola and Kamens (2006) reported challenges that related to marking the work of the student with ID and scheduling academic help for her. Interviews with the TCs and the instructor in this study revealed that they felt challenged by a lack of information about the student with ID, and they questioned whether a curriculum class was the right fit for her. Other challenges included understanding online communications from the student with ID, boundary issues with regards to online communications, and frustration that the student with ID was not 
given more academic responsibilities as a student. These challenges contribute to what we know about IPSE, especially when it is in the context of a professional program.

\section{Limitations and Further Research}

The small sample size and convenience sampling limited this study. The convenience sampling used in this study yielded only female volunteers. Further research should strive to have both male and female TC participants to ensure that the views of a more representative sample of TCs are captured. Additionally, the course instructor was a graduate student with limited experience teaching drama curriculum. Further research should study IPSE in courses taught by instructors more representative of university faculty in terms of experience instructing courses being studied. Changes in the TCs' interactions with Laura were observed in the classroom and discussed by the participants in interviews, consistent with the purpose of the study. If researchers wanted to make generalizations about changes in attitude toward individuals with ID as a result of an IPSE experience, a methodology using validated attitudinal surveys would need to be employed.

Although case studies offer limited generalizability, it has been the aim of this study to describe not only the observed behaviour of the participants, but the context of that behaviour as well, to render it meaningful to others, so that what is gained is a thick description (Geertz, 1973). Therefore, I hope that any findings that emerge from this study can be used to make comparisons and contrasts with other IPSE case studies, with knowledge and best practices produced by the preponderance of evidence found in these separate case studies.

\section{Reflections on IPSE in a Teacher Education Program}

Although much has been reported on the benefits of IPSE for students with ID (e.g., Weinkauf, 2002; Zafft et al., 2004), little has been written about the benefits of IPSE for students without disabilities. This is particularly true in the context of a 1-year teacher education program. This study is unique amongst the literature on IPSE in that it reports the views of TCs from a 1year teacher education program as they learn alongside a peer with ID. Since the student with ID was their peer, and not one of their students while on a practicum, the TCs were free from the sense of having to teach to Laura in addition to other students. Allowing individuals to see firsthand the abilities of a person with ID as a learner and a peer in a structured environment could contribute to a positive shift in their perspectives on people with disabilities (Acton \& Zarbatany, 1988).

Such a shift in teachers is important, as teachers are the prime implementers of policies on inclusion in education. Previous research on teachers' beliefs toward inclusion of students with ID has produced both positive (e.g., Stanovich, 1999) and ambivalent (e.g., Cardona, 2009) findings. Importantly, Ryan (2009) interpreted the findings of a survey of 141 TCs to mean that TCs believed they needed more training to feel confident in inclusive classrooms. As well, Stanovich and Jordan (2004) found that teachers' beliefs toward inclusion of students with disabilities in their classrooms can be affected by previous success or failure at including students with disabilities. Teachers who receive resources and supports for inclusion are more likely to experience success, raising their sense of efficacy about inclusion (Stanovich \& Jordan, 2004). As a result, these teachers are more willing to teach inclusive classes in the future. However, this cycle can also be negative - teachers who are expected to teach inclusively but who do not receive appropriate supports and resources may not experience success. This in turn can lead to a lower sense 
of efficacy, which causes these teachers to become more negative about inclusion (Stanovich \& Jordan, 2004).

While the inclusive drama curriculum class did not offer the TCs training on implementing inclusive practices, it did give them the opportunity to see inclusion in action and to learn about disabilities from interacting with the student with ID. Their remarks in the second set of interviews indicated that they appreciated the opportunity to learn alongside someone with ID. They mentioned several concrete examples of how the experience would influence their future teaching. The examples the TCs cited indicate that they have engaged in thinking about putting theory into practice and suggest a sense of efficacy in their ability to do so.

However, data from the interviews of the TCs and the drama curriculum instructor, as well as from observations of the drama curriculum class, raised the concern that a professional program such as the teacher education program may not be the best fit for IPSE. The structure of a professional program - that it must cover specific material in a specific length of time in order to remain accredited - creates a unique set of challenges for IPSE that warrants inspection. The data in this study underscored the sentiment that perhaps a drama curriculum course in a teacher education program would not provide the student with ID with the same opportunities to connect and participate as would be available in an undergraduate drama course. For instance, the first set of interviews with three of the TCs, as well as with the drama curriculum instructor, made reference to the fact that because the student with ID was not a teacher education student she might have a difficult time connecting with the TCs and with the curriculum. While connecting with TCs may be difficult for a student who is not in the teacher education program, a student with ID who had a segregated high school experience would likely encounter an initial difficulty connecting with university classmates, regardless of the university course being audited. The benefit of auditing a curriculum course in a teacher education program is the small class size and the participatory, collaborative nature of the course. This also facilitates the ease with which classmates can connect with a student with ID. As well, students in a professional, after-degree teacher education program are expected to demonstrate the maturity required in the teaching profession. This is a direct benefit to the student auditing the course, as it promotes maturity through modelling by same-age peers.

A concern expressed by the drama curriculum course instructor was that she could not make the theory aspect of the course relevant to the student with ID because it pertained to teaching, and the student with ID was not going to participate in a teaching practicum or become a teacher. The drama curriculum instructor said that attempting to explain theory at a level accessible to the student with ID would require her to present concepts to the TCs in too basic a fashion, which would be inappropriate given that the TCs have already graduated with a bachelor's degree and require the theoretical component of their program. Again, regardless of the university course being audited, this will present a concern. Theoretical-based learning is a hallmark of university education; even at the undergraduate level an instructor may have difficulty presenting some theories at a level that can be understood by a student with ID, while still presenting ideas appropriate for the rest of the class. In the case of IPSE in a teacher education program, learning theories of pedagogy should not be considered the primary motive for a student with ID auditing a curriculum course. CALC Prep, where the participant with ID was prepared for IPSE, considers the opportunity to interact with and learn from non-disabled peers to be of primary importance in IPSE. Indeed, data from previous studies, as well as this study, indicate that being social with same-age peers is important to IPSE participants with ID (CasaleGiannola \& Kamens, 2006; Hamill, 2003; Wintle, 2010). Learning new things is also important; 
however, these "new things" do not have to be theoretical. The student with ID, for instance, reported that her favourite thing from the drama curriculum class was learning about play writing (Wintle, 2010).

A TC and I both raised the concern of disruptions in the teacher education program. Each semester is disrupted by practica that see the TCs leave for blocks of practice teaching. The TC reported that the student with ID increasingly participated with each class, and that she was afraid that such a long break away from the drama curriculum class might cause the student with ID to "crawl back into her shell" and not feel as comfortable with the TCs when they returned from practicum (O., int. 2). I noted that there are many disruptions even when the TCs are not on practicum, such as workshops, that result in fewer classes. I questioned if the amount of time the student with ID would be spending with the TCs would allow for enough social interaction to benefit her. This is a concern that cannot be easily ameliorated within the teacher education program. If, however, students with ID auditing courses in the teacher education program were to simultaneously audit a second course of their interest in another faculty, regressing from a lack of interaction with peers would not be an issue. Alternatively, auditing could take place in the faculty of education in the fall semester when TCs spend more time on campus before leaving for practicum than they do in the winter semester. Additionally, the TCs' concern about not being given enough information about participant learning expectations could be addressed by a presentation on IPSE by CALC Prep, which can include being given more information about the student with ID before she or he joins the course. Furthermore, the designated buddies that offer academic support to the student with ID would benefit from having the opportunity to meet the student with ID before she or he joins the class.

Despite the misgivings raised in the data, when evaluating whether or not a teacher education program is an appropriate venue for IPSE one cannot disregard the mutual nature of its benefits. As future educators, TCs want to promote student success, making teacher education programs ideal for the inclusion of adults with ID. However, the benefits of IPSE also extend to the TCs, who profit from seeing theory put into practice, learning about disabilities, and seeing that people with ID are capable of learning. The growing trend toward integration of students with ID in Canadian schools means that these TCs will likely be expected to teach students with ID when they become teachers. Their experiences in IPSE will serve to help them fashion their own truly inclusive classrooms.

\section{References}

Acton, H., \& Zarbatany, L. (1988). Interaction and performance within cooperative groups: Effects on nonhandicapped students' attitudes towards mentally retarded peers. American Journal on Mental Retardation, 93, 16-23. Retrieved from http://www.aaiddjournals.org/

Campbell, J., Gilmore, L., \& Cuskelly, M. (2003). Changing student teachers' attitudes towards disability and inclusion. Journal of Intellectual and Developmental Disability, 28, 369-379. doi:10.1080 $/ 13668250310001616407$

Cardona, C. M. (2009). Teacher education students' beliefs of inclusion and perceived competence to teach students with disabilities in Spain. The Journal of the International Association of Special Education, 10, 33-41. Retrieved from http://www.iase.org/?journal,7

Carroll, S., Petroff, J., \& Blumberg, R. (2009). The impact of a college course where pre-service teachers and peers with intellectual disabilities study together. Teacher Education and Special Education, 32, 351364. Retrieved from http://tes.sagepub.com/content/32/4/351.abstract

Casale-Giannola, D., \& Kamens, M. W. (2006). Inclusion at a university: Experiences of a young woman with Down syndrome. Mental Retardation, 44, 344-352. doi:10.1352/0047-6765(2006)44[344:IAAUEO]2.0 . $\mathrm{CO} ; 2$ 
Dewalt, K. M., \& Dewalt, B. R. (2002). Participant observation. Walnut Creek, CA: AltaMira Press.

Donaldson, J. (1980). Changing attitudes toward handicapped persons: A review and analysis of research. Exceptional Children, 46(7), 504-514. Retrieved from http://journals.cec.sped.org/ec/

Eiginbroad, R., \& Retish, P. (1988).Work experience employers' attitudes regarding the employability of special education students. Career Development for Exceptional Individuals, 11, 15-25. Retrieved from http://cde.sagepub.com/

Esposito, B. G., \& Peach, W. J. (1983). Changing attitudes of preschool children toward handicapped persons. Exceptional Children, 49(4), 361-363. Retrieved from http://journals.cec.sped.org/ec/

Forlin, C., Douglas, G., \& Hattie, J. (1996). Inclusive practices: How accepting are teachers? International Journal of Disability, Development and Education, 43, 119-133. Retrieved from http://www.tandf.co.uk /journals/titles/1034912x.asp

Geertz, C. (1973). The interpretation of cultures: Selected essays. New York, NY: Basic Books.

Hamill, L. B. (2003). Going to college: The experiences of a young woman with Down syndrome. Mental Retardation, 41, 340-353. doi:10.1352/0047-6765(2003)41<340:GTCTEO >2.0.CO;2

Hart, D., Grigal, M., \& Weir, C. (2010). Expanding the paradigm: Postsecondary education options for individuals with autism spectrum disorder and intellectual disabilities. Focus on Autism and Other Developmental Disabilities, 25, 134-150. doi:10.1177/1088357610373759

Hodapp, R. M., \& Dykens, E. M. (2007). Behavioral effects of genetic mental retardation disorders. In M. C. Roberts (Ed.), Handbook of intellectual and developmental disabilities (pp. 115-131). Secaucus, NJ: Springer-Verlag.

Hutchinson, N. L. (2010). Inclusion of exceptional learners in Canadian schools: A practical handbook for teachers (3rd ed.). Toronto, ON: Pearson Education Canada.

McMillan, J. H., \& Schumacher, S. (2006). Research in education: Evidence based inquiry (6th ed.). Boston, MA: Pearson Education.

Miller, D., \& Salkind, N. J. (2002). Handbook of research design and social measurement (6th ed.). Thousand Oaks, CA: Sage.

Mosoff, J., Greenholts, J., \& Hurtado, T. (2009). Assessment of inclusive post-secondary education for young adults with developmental disabilities. Retrieved from Canadian Council on Learning website: http://www.cclcca.ca/ccl/Research/FundedResearch/20091204AssessmentYoungAdultsDevelopmentalD isabilities.html

Neubert, D. A., \& Moon, M. S. (2006). Postsecondary settings and transition services for students with intellectual disabilities: Models and research. Focus on Exceptional Children, 39(4), 1-8. Retrieved from http://www.lovepublishing.com/catalog/focus_on_exceptional_children_31.html

Neubert, D. A., Moon, M. S., Grigal, M., \& Redd, V. (2001). Post-secondary educational practices for individuals with mental retardation and other significant disabilities: A review of the literature. Journal of Vocational Rehabilitation, 16, 155-168. Retrieved from http://www.iospress.n1/loadtop/load.php ?isbn $=10522263$

Patton, M. Q. (2002). Qualitative research and evaluation methods (3rd ed.). Thousand Oaks, CA: Sage.

Philpott, D. (2001, winter). Inclusive education: Reviewing criticism to find direction. The Morning Watch, 28(3-4). Retrieved from http://www.mun.ca/educ/faculty/mwatch/nmwatch.htm

Rapley, M. (2004). The social construction of intellectual disability. Cambridge, UK: Cambridge University Press.

Ryan, T. G. (2009). Inclusive attitudes: A preservice analysis. Journal of Research in Special Educational Needs, 9, 180-187. doi:10.1111/j.1471-3802.2009.01134.x

Schalock, R. L., Borthwick-Duffy, S. A., Bradley, V. J., Buntinx, W. H., Coulter, D. L., Craig, E. M.,...Yeager, M. H. (2010). Intellectual disability: Definition, classification, and systems of supports (11th ed.). Washington, DC: American Association on Intellectual and Developmental Disabilities.

Stake, R. (1994). Case studies. In N. K. Denzin \& Y. S. Lincoln (Eds.), Handbook of qualitative research (pp. 236-247). Thousand Oaks, CA: Sage.

Stanovich, P. (1999). Conversations about inclusion. Teaching Exceptional Children, 31(6), 54-58. Retrieved from http://journals.cec.sped.org/tec/

Stanovich, P., \& Jordan, A. (2004). Inclusion as professional development. Exceptionality Education Canada, 14, 169-188. 
Think College! College options for people with intellectual disabilities. (2011). For professionals. Retrieved from http://www.thinkcollege.net/for-professionals/for-professionals

Weinkauf, T. (2002). College and university? You've got to be kidding: Inclusive postsecondary education for adults with intellectual disabilities. Crossing Boundaries. An Interdisciplinary Journal, 1(2), 28-36. Retrieved from http://steps-forward.org/pdf/College_and_University_You_ve_Got_to_be_Kidding.pdf

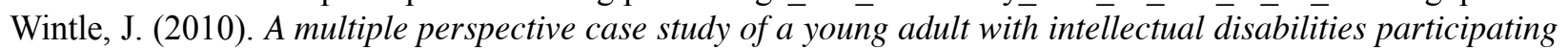
in a university class. Unpublished master's thesis, Queen's University, Kingston, ON, Canada.

Yin, R. K. (2006). Case study methods. In J. L. Green, G. Camilli, \& P. B. Elmore (Eds.), Complementary methods in education research (pp. 111-122). Washington, DC: American Educational Research Association.

Zafft, C., Hart, D., \& Zimbrich, K. (2004). College career connection: A study of youth with intellectual disabilities and the impact of postsecondary education. Education and Training in Developmental Disabilities, 39, 45-53. Retrieved from http://daddcec.org/Publications/ETADDJournal.aspx

\section{Author's Note}

Correspondence concerning this article should be addressed to James Wintle, School of Rehabilitation Therapy, Louise D. Acton Building, 31 George Street, Queen's University, Kingston, ON, Canada, K7L 3N6. E-mail: 3jjw@queensu.ca

The author would like to acknowledge and thank Dr. Nancy L. Hutchinson for her thoughtful suggestions and support. 